\title{
South African responses to Open Access publishing: a survey of the research community
}

\author{
Allison Fullard ${ }^{\text {I }}$ \\ Research Librarian Centre for the Study of Higher Education, \\ University of the Western Cape, Private Bag XI7 Bellville 7535, South Africa \\ afullard@uwc.ac.za
}

Received: $10^{\text {th }}$ May 2006

Accepted: $10^{\text {th }}$ November 2006

\begin{abstract}
Open access publishing offers wide benefits to the scholarly community and may also afford relief to financially embattled academic libraries. The progress of the open access model rests upon the acceptance and validation of open access journals and open archives or institutional repositories by the academic mainstream, particularly by publishing researchers. To what extent are the key actors in the South African research system aware of the advantages of open access? This article reports on the findings of a recent survey undertaken to assess the current awareness, concerns and depth of support for open access amongst local researchers, research managers and policy makers in South Africa. The study focuses on issues of quality, article or author charges and the established academic reward system. It concludes that within the prevailing framework, there is little prospect that academics would choose to publish within open access journals. Recommendations for advocacy by the library community are proposed.
\end{abstract}

Keywords: open access, scholarly publishing, journals, survey

\section{Introduction}

While those in the library and information profession, particularly those working in the academic library environment, are alive to the potential for open access publication to unlock content that may previously have been barred to their users, it is uncertain to what extent South African academics and researchers are aware of open access platforms as an option for publishing their work. This question is of critical importance for the progress of open access publishing since, without their acceptance and validation by the academic mainstream, it is unlikely that open access journals and archives (also known as "repositories") can become widely established and valued as sites for publishing or accessing research articles.

Inasmuch as researchers are strongly tied to the core journals in their fields of study, the familiar and respected titles that showcase the recent findings of their peers, it seems that they would be unlikely to choose relatively unknown or unproven platforms as vehicles for publication. Since published articles represent the investment of much time and effort, build an author's scholarly reputation and are used to motivate for academic rewards such as tenure, promotion or future research grants, decisions about where to publish are not lightly taken. Bjork (2004) has identified the academic reward system as one of the obstacles facing the open access movement.

This article reports on aspects of the findings of a survey undertaken to investigate to what extent stakeholders in the local research system are aware of open access publication as an alternative to branded journals. The survey also aimed to gather information to establish perceptions about the quality of open access articles and whether universities and research organizations are presently adapting existing practices and policies for evaluating research so that they are inclusive of open access publication.

The main research question that prompted the survey was to establish the likelihood of the widespread uptake of open access journals in South Africa. From the perspective of academic librarians, this question begins to anticipate the possibility of corresponding relief from the exorbitant costs of annual subscriptions and licences. It is understood that, in order for this to occur, there would need to be a significant swing towards open access as the predominant model. While these journals currently represent just $5 \%$ of all peer-reviewed journals, Hedlund, Gustafson \& Bjork (2005:204) have shown that, by 2002, nearly one third of all new journal titles were already open access. It is anticipated that authors' positive responses to these offerings would create the condition for a subsequent "tipping point" where the subscription model becomes the exception rather than the norm.

It is widely accepted that, while open access means the free availability of research material for readers, the publishing enterprise (including both commercial and not for profit publishers) will still need to generate income to cover costs and to invest in development of their publications. Since it is the process of preparing manuscripts for publication that incurs most costs, with Internet distribution being very cheap in comparison, author fees appear to be a logical way to fund the publication process. The economics of open access focuses on costs at the production end of the publication cycle to free

I. Allison Fullard is a Research Librarian, Centre for the Study of Higher Education University of the Western Cape, South Africa 
up costs on the distribution end. Author fees or article charges are used as the business model by a few well-known open access publishers, notably BioMed Central and Public Library of Science. Several mainstream publishers (Springer and Blackwells, for instance) are experimenting with open access and have introduced "author's choice", a mechanism that allows authors to opt to pay article charges in order to render such articles open access. While less than half of existing open access journals levy such fees (Kaufman 2004) and authors in developing countries are exempted from these charges, it was considered important to test the views of local researchers about the prospect of article charges.

\section{Previous studies}

Since open access is disruptive of a protocol that has been in practice for several centuries, those sectors that have a direct interest in the promise or threat of this new publication model - government bodies, publishers, research funders, amongst others - have commissioned studies to discover whether open access represents a viable alternative. An eightmonth inquiry was conducted under the supervision of the Science Committee of the UK House of Commons during 2004. The Committee examined experts' submissions and heard public evidence provided by representatives from the scholarly publishing industry, librarians, academics and government departments. Amongst the recommendations in the official report (Science \& Technology Committee 2004a) was strong support for the establishment of institutional repositories at all British universities and a proposal that further research be made with regard to the "author pays" business model of open access journals. The Joint Information Systems Committee (JISC) in the UK has contributed two important studies. One project (Swan \& Brown 2004) entailed a survey of two groups of authors, those who had published in open access journals and those who had not. It found that the prime reason authors had not submitted to open access journals was that they were not aware of suitable titles in their field. This raises the question of the role that librarians might play in advocating and raising faculty awareness of suitable open access channels. The other JISC study (Waltham 2005) provided a close investigation of the business and pricing models of nine learned society publishers and their experiments with "author's choice". Waltham reports that there has not been a strong "pull" from the author community, despite increased support from funding agencies that are willing to cover the cost of article charges. One major research funder, the Wellcome Trust, has mandated that all the research it funds be deposited in an open archive, or published via an open access journal. Its own study of the author pays model (Wellcome Trust 2004: 22) concluded that "[o]pen access author-pays models appear to be less costly and to have the potential to serve the scientific community successfully".

Besides these studies by stakeholders, individual researchers have conducted independent research. These studied author opinion (Rowlands, Nicholas \& Huntingdon 2004), assessed the author-pays model (King \& Tenopir 2004), and measured how open access influences individual articles' impact factor within different disciplines (Brody et al 2005). Bjork (2004) has contributed a study of the potential obstacles that might prevent or delay the broad uptake of open access.

In South Africa, the only previous study was conducted by De Beer (2005) and found very limited knowledge and experience of open access amongst faculty in the disciplines of computer-, library- and information sciences. She also visited the websites of over 200 academic units at Stellenbosch University to detect any evidence of self-archiving or participation in open access journals. Interestingly, she found more investment in open access amongst humanities and social sciences than amongst the units representing the natural sciences.

\section{Survey targets}

The survey was aimed at three different groups of stakeholders in South Africa: publishing authors, research managers at universities, and official research organisations that are responsible for developing research policies or that produce leading research.

Because academics and scientists are the prime change agents who will, through their publishing behaviour, determine whether open access journals become widely accepted as a platform for publication, this group was an important target for the survey.

The study focused on recently published authors in biomedical fields. This delimitation was chosen for three reasons. Firstly, biomedicine is one of the more richly endowed research areas, possibly because it represents one of the strategic frontiers of science. Since biomedicine tends to be well funded, it is a field that is more easily able to accommodate the imposition of author fees. It was considered more important to ascertain the response of authors towards the idea of article charges than to probe their affordability at this exploratory stage. Secondly, BioMed Central already fields a portfolio of 130 reputable open access journals that span the breadth of biomedical specialities, so that it is likely that researchers have encountered them. Lastly, PubMed Central, the open archive of online biomedical articles hosted by the U.S. National Library of Medicine, is a well-known source of freely available peer-reviewed articles. In short, this field was SA JnI Libs \& Info Sci 2007, 73(I) 
Only roughly half of the respondents feel confident in the peer review process of the open access journals they have encountered. The perception that these journals lack rigour appears to linger. Particularly where article charges are applied, there remains a suspicion that the publishers will accept articles in order to generate income. One research manager commented, "open access has many virtues, but so far is not associated with excellence". Across each of the groups, there were repeated comments expressing concern about quality, reflecting the importance that branded journals holds for the academic community. "Quality is the most important consideration. Access and savings are second to quality but also very important" (Organisation).

The Author group had been separately asked to rank the factors that were important when choosing where to submit their articles. Speed of publication had not rated highly (7th out of 10 factors). Yet this is a property that they associate with open access journals - perhaps believing that the peer review is brief and skimpy? The criterion that ranked the highest was the impact factor of the journal. These are the titles that will promote their standing amongst their peers and provide evidence of the value of their work to review committees. The culture of the high impact journal is fully embedded within their practices. It is worth noting that the previous enthusiasm the group indicated for the visibility and impact potential of open access has markedly deflated under closer questioning. Notionally they agree about the benefits of open access, but once they begin comparing open access journals with the journals they know and value, their uncertainty grows.

One of the policy-making organizations that responded to the survey remarked, "It is about time the so-called high impact journal died, it is so detrimental to the majority of scientists/researchers in preferential publication and research area". In other words, the high impact journal is seen to be the last word of authority, but this has become restrictive to both the scientists and to the research field. From the open access point of view, the high impact journal also carries an inflated price that restricts access to the high quality work published within it. This is borne out by the lowest rating $\left(10^{\text {th }}\right.$ out of 10) given to the price of a journal by the researchers as a consideration for their publication choice. The cost of a journal for prospective readers is of relatively low importance within their quest for peer recognition. This is ironic since open access will provide the widest possible readership for their work.

The groups' uncertainty regarding the accreditation status of open access journals is certainly a factor of the newness of many of these publications. Defining their status would place an important seal upon their recognition (where warranted) and so increase their uptake as publications of choice. As a researcher commented, "quality and standards reflect the credibility of individual journals, rather than whether the research is open access or not". In other words the journals will stand or fall based upon their own merits.

Figure 2 details the groups' overall perceptions of the quality of open access articles.

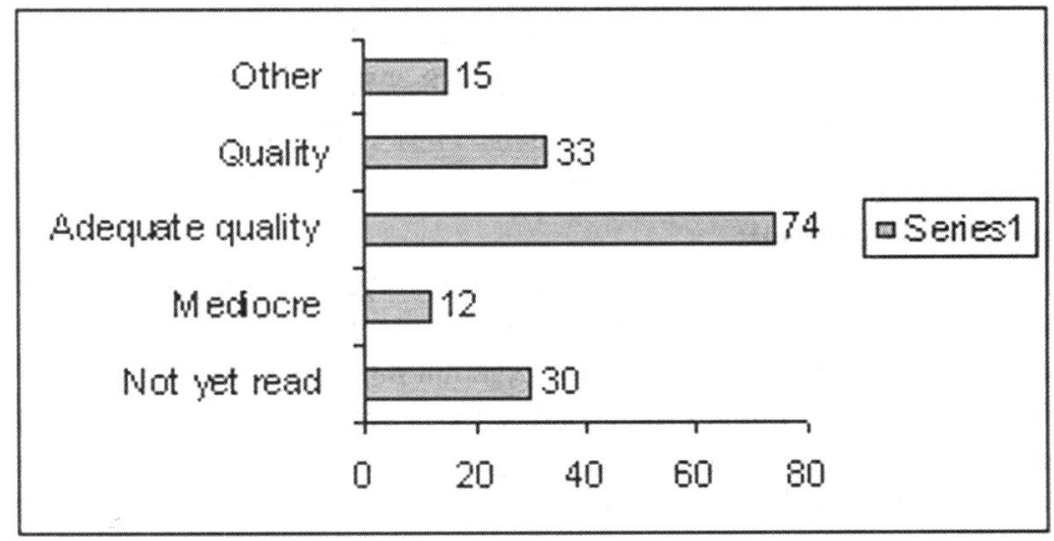

Figure 2 Perceived levels of quality of open access articles

\section{The issue of article charges/author fees}

Researchers are simultaneously readers and authors. As authors, they require the services of a publisher to administer peer review of their work and to disseminate their articles. In this way, authors are the main beneficiaries of a service. Furthermore, following publication, authors enjoy enhanced stature amongst their peers.

Article processing fees are based on the premise that authors and their host institutions are the most direct beneficiaries of publication in scholarly journals. ...Article processing charges thus distribute a journal's 
publishing costs across those individuals and institutions that benefit most directly from a paper's publication (Open Society Institute 2004: 17)

Biomed Central, an open access journal publisher that uses the 'author pays' business model, has commented:

The present system, in which smaller universities effectively subsidise the cost of publishing the research carried out at relatively wealthy research centers, is far more inequitable and unsustainable (BioMed Central 2004).

The questionnaire provided the respondents with information regarding the author pays model and explained that it appeared that 'net reader' institutions would appear to gain while research-intensive institutions would shoulder the cost of making their publications free for everyone else. Again, respondents were faced with a series of statements to which they might agree or disagree.

Table 3 Respondents' views on article charges $(\mathrm{N}=163)$

\begin{tabular}{llllll}
\hline Responses to Article Charges & A/S & A & N/S & D & D/S \\
\hline Author charges are an appropriate cost-recovery system & 9.20 & 42.95 & 23.94 & 20.85 & 3.06 \\
An equitable way of redistributing resources within the research system & 4.29 & 41.11 & 34.36 & 16.56 & 3.68 \\
Author charges appear to present a disincentive to publish & 7.36 & 30.07 & 32.51 & 28.84 & 1.22 \\
Local journals would not survive using this business model & 6.17 & 38.89 & 41.36 & 9.88 & 3.70 \\
Overall systemic savings and improved access are the most important considerations & 9.31 & 37.89 & 37.27 & 13.67 & 1.86 \\
\hline
\end{tabular}

Besides any inherent agreement with the logic of the author pays system, it should be borne in mind that the respondents may be acquiescent of this model for two further reasons. Firstly, since the respondents are working within a developing country context, and therefore mostly exempted from article fees, they may not be troubled by the prospect of paying $\$ 1500-\$ 2500$ per article. Secondly, since South Africa is certainly a 'net reader' nation (producing only $0.2 \%$ of published articles), they may understand the scale of benefit to the country overall. Nevertheless, the group is able to hypothesise that article charges might constitute a disincentive to publish.

While international open access journals might be in a position to waive the article fees for developing country authors, local journals would not. The groups were able to foresee the difficult situation that local non-profit journal publishers might face under open access. Although they were given the opportunity to make comments about this, none did.

Overall, it was surprising to find that the notion of 'paying to publish' was not seen as an insurmountable problem for these groups. It may be that they understand how much it costs to produce research and that the imposition of article charges is a relatively low barrier for the larger prize of universally accessible dissemination of this cost-intensive activity. They were also asked to identify agencies that should bear the cost of article charges. Although one researcher commented, "this is a minor issue", most opted for some combination of research funder, author's institution, government department, or funds freed from the demise or cancellation of journals charging traditional subscription or licence fees.

\section{Academic rewards}

As mentioned above, it is certain that authors are likely to be highly selective when submitting manuscripts to a journal. Beyond the statements affirming belief in the advantages of open access, the groups' cautious approach to the quality of open access journals, or their responses to article charges, specific concerns that the author group might hold with regard to the academic reward system were also tested. Did they believe that publishing in an open access journal might jeopardise their future career opportunities? Would they wish to see greater endorsement of the open access philosophy by research managers and organisations such as the National Research Foundation and the Dept of Education? What strategies might be employed to bring this about? Alternatively, were they anxious about the threat that open access might appear to present to existing subscription journals? The following question was borrowed from Swan \& Brown (2004).

Table 4 Researchers' views on the consequences of their choice to publish in open access. Journals $(N=\mid 45)$

\begin{tabular}{llll}
\hline Publishing in an open access journal $(\mathbf{N}=\mathbf{~ 1 4 5})$ & Agree & Disagree & Not sure \\
\hline May adversely affect my chances of appointment/promotion & 26.39 & 39.58 & 34.03 \\
May adversely affect the careers of my co-authors & 20.83 & 38.89 & 40.28 \\
May adversely affect the potential impact of my published work & 31.72 & 37.24 & 31.04 \\
May adversely affect the economic viability of scholarly society journals & 36.11 & 21.53 & 42.36 \\
\hline
\end{tabular}


While they express more confidence than reservation in each of the first three statements, the high level of uncertainty across the board is indicative that these questions remain largely untested in reality. Of the 145 researchers, only 32 (22\%) had already published in open access journals, a further 19 were not sure whether they had, and 94 have not. While $79 \%$ express a desire for greater recognition of the open access journal, $8.5 \%$ would not want this and $10.8 \%$ had other comments to make. The comments range from uncertainty ("too early to say"; "would need to know more"), provisos ("only for those which have a rigorous review process and maintain high standards of quality"; "only if this became the norm internationally"), skepticism ("not if it is going to cost so much") and support ("It is essential that consideration be given to including appropriate open access journals in the list of subsidy earning journals").

Figure 3 shows the ways that researchers believe that open access could be fostered more widely. They could tick as many options as they believed feasible and applicable to the local system.



Figure 3 How Researchers believe open access might be promoted

The eleven university research managers were asked how their institutions might bring about greater awareness of open access. Most selected options such as communications distributed to research networks on campus or a library-led awareness campaign ( 10 of $\mathrm{II}$, for both of these). Postgraduate or professional development workshops were also viewed as a reasonable route for promotion $(7$ of $\mathrm{II})$. Cross-departmental workgroups or the institution's research ethics structure received less support ( 5 and 3 of $1 \mathrm{I}$, respectively).

The Research Organisations/policy makers group was asked to identify specific programme areas within their organisations that would benefit from the outcomes of open access publishing. The answers that were prompted appear in Figure 4.

Several of these signal the importance of open access for developing research capacity.

- Training, mentoring, projects in Africa, continued development of scientists

- All research fields would get access to more literature

- Our programme areas do involve postgraduate training and we hope to involve students and scientists from elsewhere in Southern Africa from institutes that would greatly benefit from increased access to research material

- Enhancing research capacity at a national systems level in relation to the science \& technology needs of S.A.

- Research and higher degree studies generally

- All activities

- As an organisation will benefit, however it is difficult at this time to identify individual areas that will benefit most. It is anticipated that Open Access publishing will motivate the individual researcher to publish more than he did in the past.

- Basic research and application of latest research techniques

Figure 4 Programme areas that would benefit through open access publishing 


\section{Current and future prospects for open access within SA research institutions}

While it is the actions of researchers that will influence the sway towards widespread uptake of open access, this can be hastened or impeded by the official stance of those in positions of authority. Table 5 presents the current situation within the respondents' institutions (individuals could respond to as many options as were applicable to them):

Table 5 The current status of responding institutions' policies on open access

\begin{tabular}{lll}
\hline Current status of open access policies & Managers & Organisations \\
\hline OA publishing has not yet been discussed at business meetings & 6 of II & 6 of 7 \\
OA publishing has been raised, but not yet taken forward & 4 of II & 0 of 7 \\
$\begin{array}{l}\text { Is developing a policy on OA publishing with regard to the research it funds } \\
\begin{array}{l}\text { Is developing a policy with regard to recognizing OA publications as part of its academic review or grants } \\
\text { making processes }\end{array}\end{array}$ & I of II II & 0 of 7 \\
$\begin{array}{l}\text { The university is developing an OA archive that will collect and preserve its digital research outputs / The } \\
\text { organization is developing an OA policy with regard to its own output }\end{array}$ & I of 7 \\
\hline
\end{tabular}

It is not clear how progress could have been made with respect to the last option without explicit approval via the first option. It is possible that institutional archives are being established as part of an overall preservation strategy or as a showcase of the institution's research activities, independently of any official stance on open access. From these responses it seems clear that the premier research organisations are lagging in placing open access on their agenda.

Notwithstanding the present status, respondents within the Manager and Organisation groups were asked to rate the chances of several strategic interventions being supported within their institutions, see Table 6.

Table 6 Prospects for endorsement of open access at policy level

\begin{tabular}{|c|c|c|c|}
\hline Likelihood of progress & Already supports & Likely to support & Need more info \\
\hline Explicitly reward open publication as a service to science & 1 of 19 & 11 of 19 & 7 of 19 \\
\hline $\begin{array}{l}\text { Urge researchers to retain copyright over their work to enable subsequent } \\
\text { self archiving }\end{array}$ & 3 of 19 & 11 of 19 & 5 of 19 \\
\hline Requiring prompt self archiving within Open Archives as a condition of funding & 0 of 19 & 15 of 19 & 4 of 19 \\
\hline Establish Open Archives for research output & 3 of 18 & 11 of 18 & 4 of 18 \\
\hline
\end{tabular}

Groups were given the opportunity to respond "would not support", but this option was not used by anyone. This is encouraging for envisaging a scenario where strong, supportive policies have been put into place, allowing open access to take root. For this to occur, further lobbying and advocacy initiatives would need to be pursued, especially given the high levels of "more information needed" responses.

\section{Answering the research question}

The purpose of the survey was to obtain empirical data to inform the research question which attempted to determine the prospects for open access publishing amongst the academic community in South Africa. The limitations of the survey (for example, the low response rate for the author target group which represents only one research field) will constrain the extent to which one may generalize for the broader population of researchers in all fields

Nevertheless, the findings above could conceivably be used as a gauge for wider responses and might be said to provide a pleasingly open yet cautious approach to open access publication. Nevertheless, it will be shown that the chances of a general swing towards open access remain highly unlikely at present.

Using the responses from the survey together with the author's knowledge and working experience with academics across several disciplines, it was possible to approach the research question by examining six necessary pre-conditions for widespread adoption of open access journals as publication channels. Extended discussion of each of these aspects is provided by the author (Moller, 2006:129-137). The following observations form an abbreviated summary:

\section{Dissatisfaction with the current problems in scholarly publishing}

- At present, $90 \%$ of SA scholarly publications emanate from 6 or 7 historically advantaged institutions where access to literature is not a severe problem. Since it is publishing authors that will make the decisive difference with regard to publishing in open access journals, these will not be experiencing high levels of dissatisfaction with the existing publishing model.

SA Jnl Libs \& Info Sci 2007, 73(I) 
- The researchers in the survey indicated that the cost of a journal had the least influence in their decision about where to publish. It is reasonably certain that others' access to their published articles is not considered important, even though this may affect the overall visibility or impact of their work.

2 An informed understanding of the principles and benefits of open access

- Stakeholders must first be aware of the principles and promise of open access in order to subscribe to these actively through their publishing behaviour. International studies (Rowlands, Nicholas \& Huntingdon 2004; Seitmann 2005) have established that over $75 \%$ of academics know nothing or very little about open access. While the present survey found that overall $60,36 \%$ of the combined groups were reasonably knowledgeable about open access, it is likely that South African scholars across the disciplines conform to the findings of these international studies. Active advocacy will be required to spread information and awareness about open access.

- The high levels of agreement on the advantages that open access would secure (with occasional mild levels of uncertainty) signals that the research community understands what could be achieved through widespread application of open access. It is not doubted that all scholars would want to see an improvement in their access to published articles.

3 An active interest in furthering the development of open access

- Whether this appreciation of the benefits would be translated into active choice for open access is a different matter. A recent survey of 780 UK academics across all disciplines found that, even where these were aware of open access, only $8 \%$ of the researchers in the physical and life sciences and $6 \%$ in social sciences and humanities currently "prefer to publish in open access journals" (Sparks 2005). This shows that knowledge of open access does not equate to changes in behaviour.

- Thirty-nine percent of the respondents in the present survey were prepared to accord open access journals equal status with traditional journals, $25 \%$ were not, while the remainder were unsure. The reluctance to commit to open access journals probably rests upon the unproven status of these publishing channels.

- Researchers have little incentive to pursue publishing in open access journals as their importance has not yet been signaled via debate within the local research system.

4 The availability of a comprehensive spread of open access journals in which to publish

- In order to be selected as publication channels, open access journals must have sufficient presence within the landscape of available journals. The Directory of Open Access Journals currently reflects I,784 peer reviewed titles. Ulrichs lists I, I 16 open access journals amongst a total of 23,995 refereed scholarly journals.

- Hedlund, Gustafson \& Bjork (2004:209) remark that marketing of open access journals has largely been neglected.

- Since South African researchers in most fields find it easier to be published within local journals, a key consideration is how many of these are open access. Only 5 open access journals produced in South Africa have been identified ( $\mathrm{De}$ Beer 2005:200-4; Moller 2006: I35-6).

5 The recognition of open access journals by review committees

- Only approved journals are subsidised by the Dept of Education (Ministry of Education 2003: 5). These are titles listed in the ISI Citation Indices, the International Bibliography of Social Sciences and the Department's own list of approved South African journals. Only 210 open access journals are included in ISI citation databases and only 2 of the 5 identified South African open access journals are currently included in the Department's list.

- Seventy-nine percent of researchers expressed a desire for greater recognition of open access journals where these met the requisite criteria. The requirements for proposing the inclusion of a South African journal in the accredited list are not onerous, but would require existing local journals to adopt an author pays model. It takes several years for new journals to achieve official impact factors through ISI and this depends upon them receiving high quality submissions.

6 The ability to pay article charges

- To the survey respondents, the idea of article charges did not appear to constitute an insurmountable obstacle to publishing in open access journals. Many local journals already levy page fees.

Guided by these observations, it is possible to forecast with some certainty that, within the prevailing framework, there is little likelihood of South African researchers choosing to publish in open access journals. There are several obstacles, the most important being: lack of incentive to pursue open access as a course of action; the enduring perception that open access journals lack rigour; insufficient information about appropriate open access journals within a given field; and the relatively small number of accredited open access journals available. The combination of these factors presents an unpromising prospect for open access journals locally.

\section{Routes for fostering the progress of open access}

Fortunately, this discouraging outlook may be averted by means of several direct and indirect interventions. The indirect interventions will occur as a result of developments within the movement towards open access itself, as it gains further 
momentum. For example, many mainstream publishers have established 'author choice' options or are converting existing journals to open access. These experiments will filter through to increase local researchers' consciousness of the drive towards open access. Additionally, with the growing number of open access articles discoverable through Google, (either self-archived or from open access journals themselves), researchers will increasingly become direct beneficiaries of open access. Through their use of the material they should recognize that open access does not inherently bring about a loss of quality. Academics serving on editorial boards of local journals may begin to push for these to experiment with variations on the existing subscription model. At policy level, virtually every month there are reports of open access being endorsed or mandated by research funders, research organizations themselves or government-led agencies. This advancing threshold is likely to become more pervasive until it reaches some 'tipping point', after which local research managers and policy makers can no longer not act in a decisive way. Similarly, it is possible that the success of local institutional repositories may send a signal to authorities that it is possible to harness technology to promote the visibility, accessibility and impact of local research.

While these developments arising out of indirect interventions are positive and desirable, and seem inevitable, they are insufficient to create a widespread swing within the South African research system. For this to occur several overt actions are necessary. The following section presents recommended courses of action.

\section{Recommendations}

Proactive direct interventions are preferable to the passive response implied by the indirect interventions above. In order to bring about the benefits of open access as soon as possible, the following courses of action are proposed.

Faculty librarians can act as change agents by informing and advocating for open access within the departments they serve. A promotional brochure of the open access movement, Create Change, urges scholars and librarians to actively pursue and promote open access channels within their institutions and lists concrete measures they may take to promote the rapid and efficient transition to open access publishing. The Create Change website 3 provides tools and an advocacy kit as well as a PowerPoint presentation that may be adapted for local use. Because the website site is sponsored by the Association of Research Libraries, there is a heavy emphasis on educating librarians on how to run an advocacy campaign.

To overcome the identified gap in awareness of open access at policy level, more organised campaigns are necessary. It is recommended that LIASA formulates nuanced position papers that address the strategic opportunities that open access presents for the functions of the Dept of Science \& Technology, the Dept of Arts \& Culture and the Dept of Education. These should be presented via formal channels, for example through appropriate Parliamentary Portfolio Committees, so that open access is inserted onto official agendas.

Other arenas for organized advocacy include organizations within the higher education sector, starting with Higher Education South Africa (HESA), the newly constituted merger of the South African University Vice Chancellors Association and the Committee of Technikon Principals. The main thrust of the lobby to this group would be towards the importance of creating institutional repositories at all universities, with a view to mainstreaming the practice of selfarchiving, to increase visibility of and access to institutional research output. The strength of support for establishing such repositories indicated by university research managers within the survey suggests that this recommendation is achievable.

The avenues for advocacy mentioned above are preliminary steps towards the actual objective: the promulgation of a legislated policy statement that mandates open access to articles arising out of publicly funded research. This position has already been proposed by De Beer (2005: 139).

Open access is a very new, dynamic, yet disruptive force that is compelling actors within the scholarly communication cycle (scholars, research funders, research evaluators, publishers, libraries) to reconsider their positions and strategies. Its fiercely attractive benefits cannot be won without considerable wrestling and reconfiguration of existing processes, protocols and mindsets. Notwithstanding the rapid growth of open access journals across all fields, it will take some time to achieve widespread changes to longstanding publishing models. The dynamic actions of South African information professionals, both through organisational intervention and through individual efforts, can influence the course of open access locally. Further research within the local setting would also provide a firm standing for advocacy. For example, a close investigation of the performance of the five open access South African journals, in terms of submissions, editorial practice and citation levels, would likely yield important information for other journals interested in the open access model. Similarly, a study of the experiences of authors that have used open access platforms may throw up further evidence of the citation advantage of open access and serve as an incentive to other researchers to opt for open access.

3. http://www.createchange.org/home.html

SA JnI Libs \& Info Sci 2007, 73(I) 


\section{References}

BioMed Central. 2004. (Mis)Leading open access myths. [Online] Available http://www.biomedcentral.com/openaccess/inquiry/ myths.pdf. Retrieved 16 October 2004.

Bjork, B-C. 2004. Open access to scientific publications - an analysis of the barriers to change? Information Research, 9(2). [Online] Available http://informationr.net/ir/9-2/paper /70.htm/ Retrieved I5 September 2004.

Brody, T., et al. 2005. Citation impact of open access articles vs. articles available only through subscription ("toll-access"). Unpublished study [Online] Available http://citebase.eprints.org/isi_study/ . Retrieved I April 2005.

De Beer, J.A. 2005. Open access scholarly communication in South Africa: a role for national information policy in the national system of innovation. MPhil thesis, University of Stellenbosch. [Online] Available http://eprints.rclis.org/archive/00003/10/. Retrieved 4 May 2006.

Hedlund, T., Gustafson, T. \& Bjork, B-C. 2004. The open access scientific journal: an empirical study. Learned Publishing, 17:199209.

Kaufman, C. 2004. Variations on open access: a study of the financial and non-financial effects of alternative business models for scholarly journals. Association of Learned and Professional Society Publishers (ALPSP). [Online] Available http:// www.sspnet.org/files/public/kaufman.pdf. Retrieved I5 April 2005.

King, D.W. \& Tenopir, C. 2004. An evidence-based assessment of the 'author pays' model. Nature (web focus). [Online] Available http://www.nature.com/nature/focus/accessdebate. Retrieved I5 September 2004.

Ministry of Education (South Africa). 2003. Policy and procedures for measurement of research output of public higher education institutions. Pretoria: Government Printer (Regulation Gazette no. 7794, 14 October 2003, (Government Gazette no. 25583) [Online] Available http://education.pwv.gov.za/content/documents/307.pdf. Retrieved 23 September 2005.

Moller, A. 2006. The case for open access publishing, with special reference to open access journals and their prospects in South Africa. Unpublished MBibl thesis, University of the Western Cape. [Online] Available http://eprints.rclis.org/archive/ 000058/5/. Retrieved 4 May 2006.

Open Society Institute. 2004. A guide to institutional repository software. $3^{\text {rd }}$ ed. [Online] Available http://www.soros.org/ openaccess/software/OSI_Guide_to_Institutional_Repository_Software_v3.htm. Retrieved I5 March 2005.

Rowlands, I., Nicholas, D. \& Huntingdon, P. 2004. Scholarly communication in the digital environment: what do authors want? Findings of an international survey of author opinion: project report. Centre for Information Behaviour and the Evaluation of Research, Dept of Information Science, City University, London. [Online] Available http://ciber.soi.city.ac.uk/ciber-pareport.pdf. Retrieved I6 April 2005.

Science \& Technology Committee. House of Commons. 2004a. Scientific publication: Free for All? [Online] Available http:// www.publications.parliament.uk/pa/cm200304/cmselect/cmsctech/399/39902.htm. Retrieved I5 September 2004.

Science \& Technology Committee. House of Commons. 2004b-c. Scientific Publication. Minutes of Evidence, March I (b) and 2I April (c) [Online] Available http://www.publications.parliament.uk/pa/cm200304/cmselect/cmsctech/399/4030101.htm, http://www.publications.parliament.uk/pa/cm200304/cmselect/cmsctech/399/4042 I0I.htm

Seitman, R. 2005. Open access is practically unknown among scientists as an alternative for publications, Heise Online, May 24. [Online] Available http://www.heise.de/english/newsticker/news/59823. Retrieved 23 September 2005.

Sparks, S. 2005. JISC disciplinary differences report. London: Rightscom Ltd. [Online] Available http://www.jisc.ac.uk/ uploaded_documents/Disciplinary\%20Differences\%20and\%20Needs.doc. Retrieved 23 September 2005.

Swan, A. \& Brown, S. 2004. JISC/OSI journal authors survey report. Truro, Key Perspectives Ltd. [Online] Available http:// wwww.jisc.ac.uk/uploaded_documents/JISCOAreportI.pdf. Retrieved I5 September 2004.

Waltham, M. 2005. JISC: Tearned society open access business models. [Online] Available http://www.marywaltham.com/ JISCReport.pdf. Retrieved 3 October 2005.

Wellcome Trust. 2004. Costs and business models in scientific research funding. [Online] Available http://www.wellcome.ac.uk/ assets/wtd003184.pdf. Retrieved I5 September 2004. 